\title{
Calibrations of Urbanization Level in China
}

\author{
Yang Wang'; Jinfeng Wang ${ }^{1,2,2} ;$ Yansui $\mathrm{Liu}^{3}$; Jie $\mathrm{Li}^{1}$
}

Urbanization is the inevitable outcome of socioeconomic development, especially after the industrial revolution in 1760 (1). Since the founding of the People's Republic of China in 1949, the urbanization of China has made great progress. The speed and mass of urbanization and notably its relevant consequences, such as resource consumption and carbon emissions, has taken place in the most populous country in the world over the past three decades, which is raising increased concerns internationally (2) (Figure 1). Urbanization rate (in this article, this indicator refers to the population urbanization rate) is a common indicator of urbanization. Many international organizations (such as the World Bank, World Health Organization, Food and Agriculture Organization of the United Nations, etc.) use urbanization as one of the important criteria for measuring productivity and economic growth in a country (1). China's urbanization process can be described as the largest population migration in history and has also had an important impact on public health. As the national population migrates from rural to urban areas, differences in lifestyle, environmental quality, social security, and accidental injuries have all been brought about and become more and more dramatic (3). Therefore, as an important socioeconomic factor, the urbanization rate index also has an important reference role in the measurement and evaluation of public health, and the accuracy of the index is also particularly important.

An urbanization rate of $50 \%$ is a key point in assessing the development level of urbanization, which is an important symbol of a country (or region) developing into an urbanized country or achieving modernization. It represents a historical change in the social structure and the mode of production (4).

However, the calibration of urbanization rate varies in time and changes for different regions and departments due to a multitude of reasons, which makes the rate problematic to capture. Conceptually, the universal urbanization rate refers to the urbanization rate of residential populations, and the calculation method is taking the ratio of the urban population to the residential population (5). The residential population is a common statistical caliber concept of the population census at home and abroad, which refers to the population who often resides in a certain area and can be divided into the urban population and the rural population according to their attribute of living (6). Furthermore, due to China's unique permanent residence registry system ("hukou") (3), registered population is another common statistical concept. Registered population is the population who has registered a permanent residence and is divided

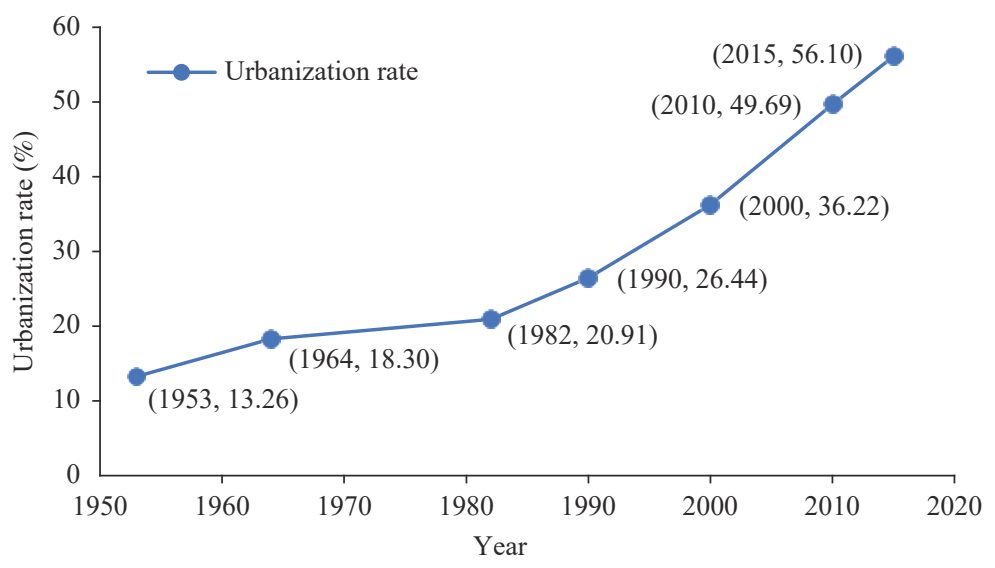

FIGURE 1. The changes in China's urbanization rate (at different year of Chinese Population Censuses and the Statistical Bulletin of the Economic and Social Development in 2015).

Data sources: Data from the 1953, 1964, 1982, 1990, 2000, and 2010 Population Censuses of China and the Statistical Bulletin of the Economic and Social Development in 2015. 
into agricultural population and non-agricultural population according to the property of registered residence $(7)$. The urbanization rate of the registered population was first proposed in 2014 (8). Prior to this, the proportion of non-agricultural population under the registered population system has often been used to represent urbanization rate.

The two urbanization rate indicators under different demographic systems used in the calculation of urbanization have brought about some problems.

The first problem is that urbanization rates are not comparable for different demographic systems. There is a wide variety of statistical data in China that use different demographic systems. Consequently, the urbanization rate indicators in these statistics cannot be

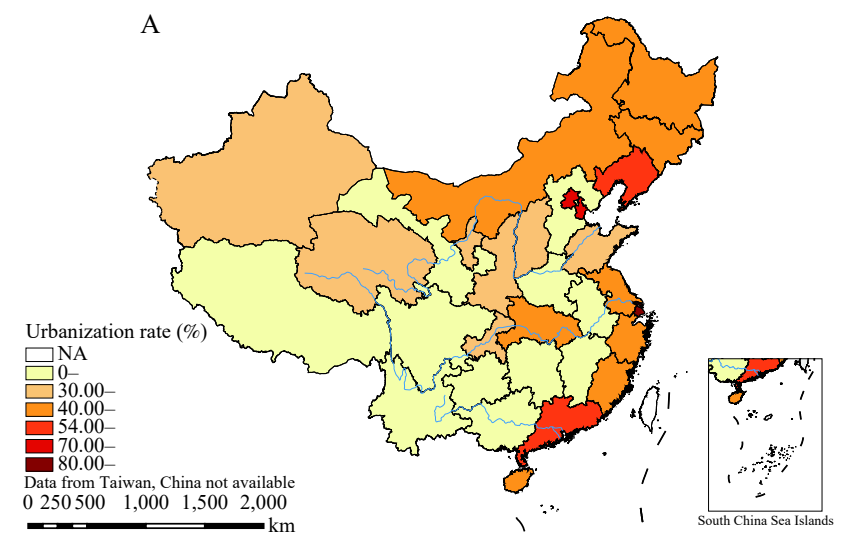

used simultaneously. If there is a mandatory comparison of the urbanization rate of different demographic systems, overestimation or underestimation will occur (Figure 2).

The second problem is that urbanization rates are less comparable in time series. With the development of urbanization, changes in the concept of statistical indicators coupled with the adjustment of administrative divisions directly resulted in changes in statistical calibers, which has had some impacts on the statistical results. This in turn influenced urbanization rates on time series even under the same demographic system. Therefore, if the same statistical caliber is used to calculate the urbanization rate for a certain time series, the result will be incomparable (Figure 3).

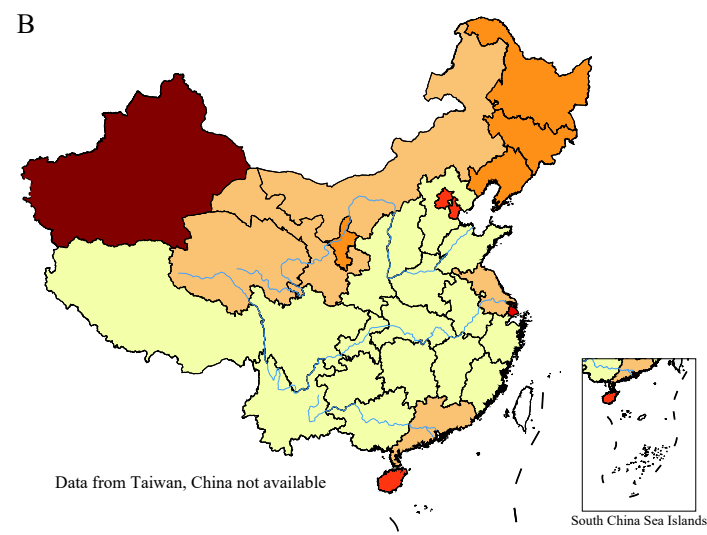

FIGURE 2. Urbanization rates under different demographic systems. (A) The proportion of urban population in 2000 National Population Census; (B) The proportion of non-agricultural population in 2000 China City Statistical Yearbook.

Data sources: the 5th Census Data (2000) and 2000 China City Statistical Yearbook. The two maps present significant difference (Geodetector $q=0.46^{\star \star *}$ ).

Abbreviation: $\mathrm{NA}=$ not available.
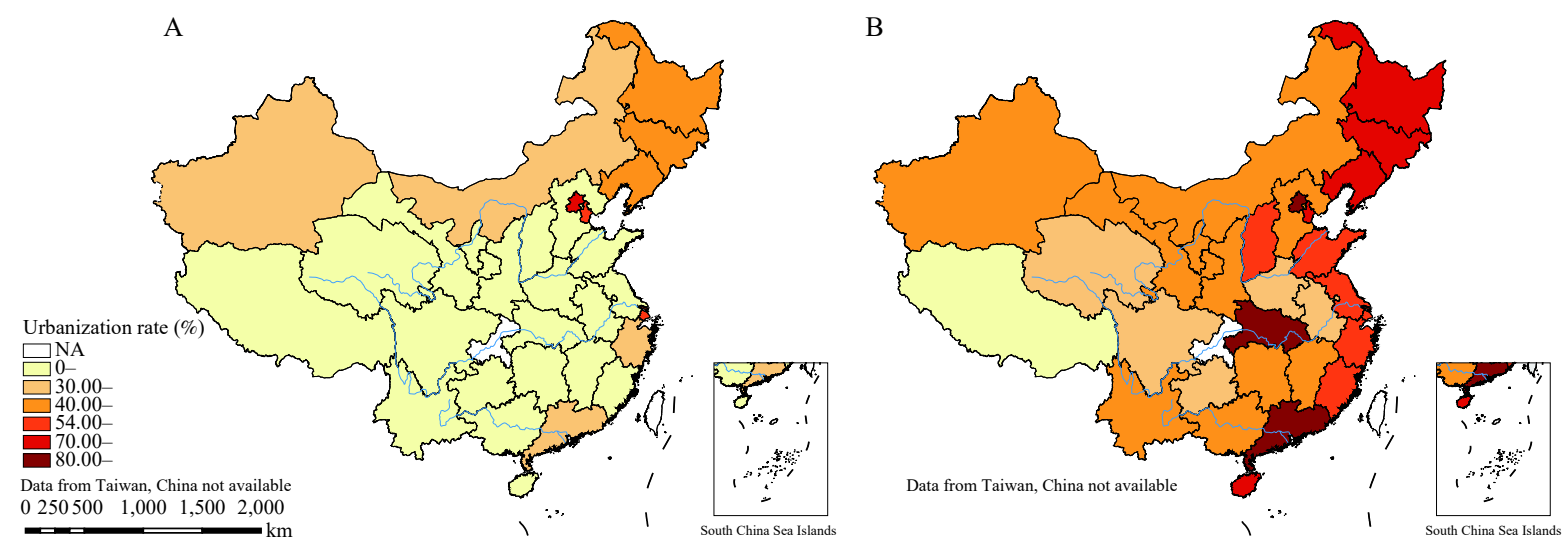

FIGURE 3. Urbanization rate of residential population calculated under different urban population statistical calibers. (A) 1990 urbanization rate in National Population Census (calculated under 1990 urban statistical caliber); (B) 1990 urbanization rate in National Population (calculated under 1982 urban statistical caliber).

Data Sources: the national population census data in 1982 and 1990 Population Census of China. The two maps present significant difference (Geodetector $q=0.36^{* * *}$ ).

Abbreviation: NA=not available. 
Similarly, for smaller statistical units, changes in urbanization rate-related indicators caused by the adjustment of administrative divisions also made it difficult to study the time series of urbanization rates (Figure 4).

Although China's current residential urban population statistical caliber basically conforms to the current internationally accepted principles and standards for urban-rural division, the urbanization rate is still highly controversial in China.

The ambiguity of China's urbanization rate has led to uncertainty in evaluating the level of urbanization and was subject to biases in urbanization-based policies.

First, the level of urbanization reflected by the urbanization rate calculated under the two demographic systems is different. As mentioned previously, an urbanization rate of $50 \%$ is the critical point in the classification of developing and developed countries. By the end of 2017, the urbanization rate of residential population in China was $58.52 \%$, while the urbanization rate of registered population was $42.35 \%$ (9). The gap between the urbanization rates under the two demographic systems will lead to some bias in judging and explaining the critical stages of social development.

Second, the permanent residence registry system exists in countries worldwide. It is a sign that the state recognizes and protects the legitimate rights and interests of the registered persons according to law. In China, the permanent residence registry system is a unique urban-rural dualistic household registration system (hukou system) (9), which is different from other countries, and the nature of the hukou is legal evidence for resource allocation and benefit distribution. Although the reform of the household registration system promoted by some cities and regions in China has somewhat weakened the classification of people in the household registration system, the hukou-related phenomenon is still a hidden existence. Taking Shanghai as an example, in 2013, the residence permit points system was first implemented. The migrant population with a residence permit and a total score of 120 points can enjoy public service treatment such as public education, off-site college entrance examination, social insurance, housing, basic public health, etc. (10). However, due to the low level of education in a large number of migrant workers, this academically-based point standard makes it difficult for migrant workers to meet the household registration standards (11). The bundling of the household registration system and the employment system also imposes various restrictions on the occupational access of migrant workers. Coupled with the limitations of the quality of migrant workers, they can only work at the bottom of the city and encounter problems such as different pay for equal work. This has also led to a labor shortage in recent years (11). The gap between the urbanization rates under two demographic systems in China is the statistical representation of this phenomenon, and the essence of this problem is the "peri-urbanization" traits of China's urbanization (12).

Third, the incompatibility of the urbanization rates in time series and different demographic systems brought difficulties to data acquisition and judgment of the urbanization level in urbanization studies, especially when long time series are involved.

In previous studies, some scholars pointed out that the urban-rural income gap and the urbanization rate showed an inverted U-shaped relationship, which is consistent with the inverted U-shaped theory of the Kuznets curve (13). This means that with the increase of urbanization rate, the income gap between urban and rural residents will increase first and then decrease. The income gap between urban and rural residents has important significance in evaluating government work performance and government macro-control, and the urbanization rates under two different demographic systems will lead to different results in measuring the urban-rural income gap. In recent years, the Chinese government has begun to pay attention to the simultaneous improvement of the two urbanization rates, at the same time, the urbanization rates under the two demographic systems have been included in the work objectives. This move is also aimed at reducing the gap between the urbanization rates under the two demographic systems in measuring the degree of development and the people's living standards.

Similarly, the environmental problems brought about by the rapid development of urban economy are also closely related to the urbanization rate. For example, in recent years, the Chinese people have suffered from fog and haze. Some scholars have shown that when the urbanization rate is at a low level (less than $60.8 \%$ ), fog and haze pollution gradually increase with the improvement of the economic development level. When the economic development level reaches a certain level, the fog and haze pollution goes from high to low. When the urbanization rate is at a high level (greater than or equal to $60.8 \%$ ), with the further increase of the economic development level, the fog and haze pollution has turned upwards. This overall process presents an N-type relationship (14). Therefore, when judging the trend of fog and haze pollution through the level of urbanization reflected by 

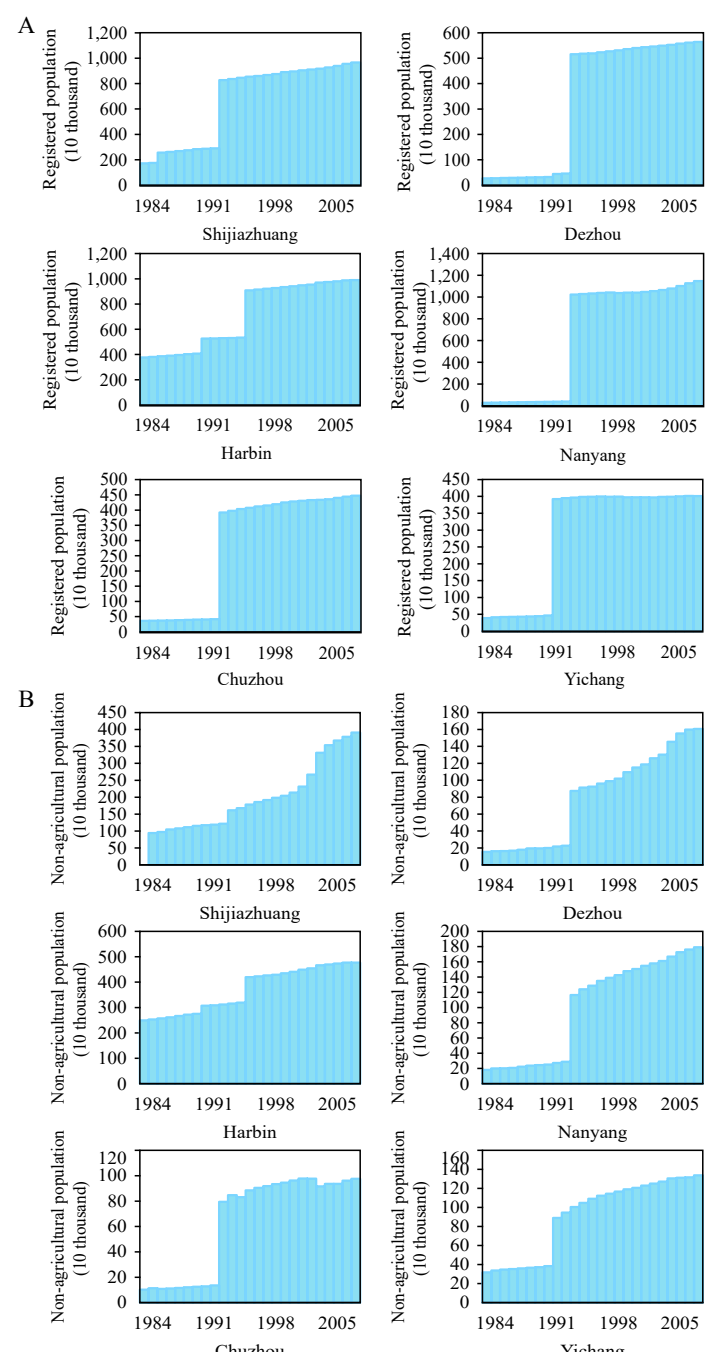

C
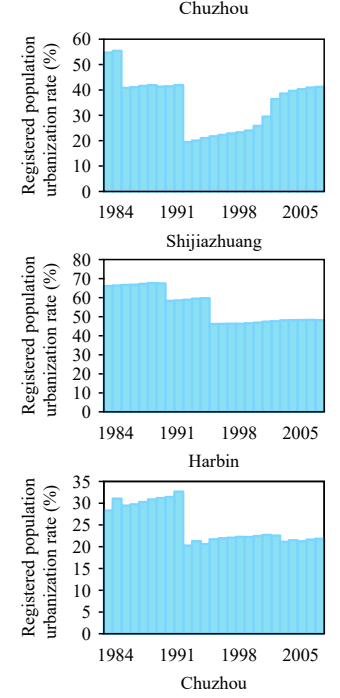
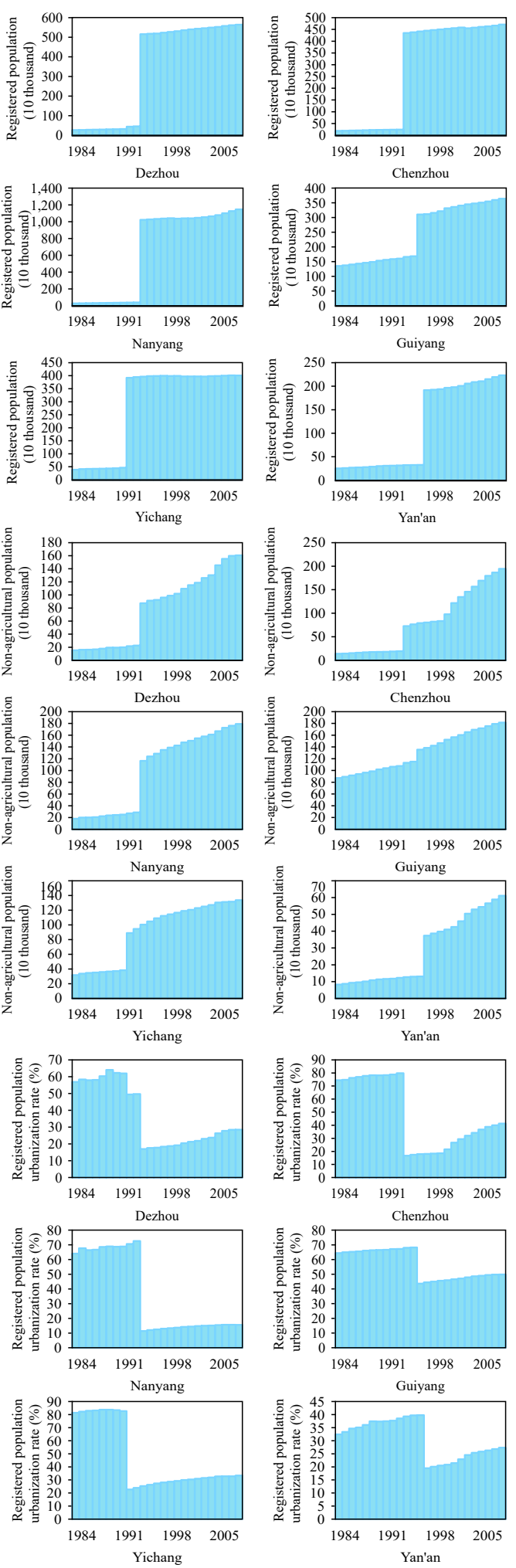
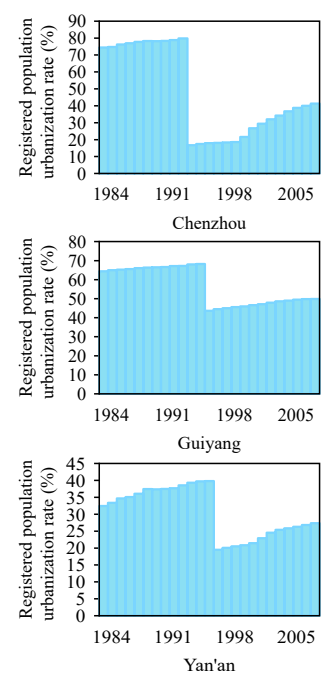

FIGURE 4. The impact of administrative division adjustment on statistical caliber. (A) The changes of registered population from 1984 to 2008; (B) The changes of non-agricultural population from 1984 to 2008; (C) The changes of registered population urbanization rate from 1984 to 2008.

Notes: According to the characteristics of statistical data and the spatial distribution of cities, here we select 9 cities which are greatly affected by the administrative division adjustment as the example cities to show the changes of statistical data.

Data sources: 1984-2008 China Urban Statistical Yearbook. 
the urbanization rate, the existence of two demographic systems will bring certain ambiguity and confusion, which will affect the fog and haze governance and industrial structure development.

Joseph Stiglitz, American economist and Nobel laureate, believes that there are two things that affect human development and change the world in the 21 st century: one is the development of the US high-tech industry, and the other is the urbanization of China. China is one of the most important economies in the world and has nearly one-fifth of the world's population, which has a major and long-term impact on the world. In the last few decades, China's ties with the world have become much closer, such as the Belt and Road Initiative, the Shanghai Cooperation Organization, etc., which has made China's spillover on the world more obvious. Moreover, China's urbanization is experiencing a period of rapid development, and the two urbanization rates have brought ambiguity to the evaluation of China's urbanization level. Therefore, in the comparative study of urbanization around the world, the differences of China's urbanization rates under the two demographic systems also need to be considered.

\section{SUGGESTIONS}

When using urbanization data, we need to pay special attention to the aspects such as the different demographic systems, adjustments of the statistical caliber, the updated significance of statistical indicators, the development level of urbanization, as well as the actual administrative divisions and policy changes.

When using the urbanization data for a single year or a single region, it is necessary to ascertain whether the statistical system, statistical concept, and statistical caliber of the urbanization data in the selected statistics are the same.

In the time series comparison and basic horizontal comparison studies, the data cannot be used directly. The most basic principle is to ensure the unity of data sources. It is also necessary to pay attention to the different effects of the old and new urban population statistical caliber on urbanization data and combine them with the specific urban composition and development of different regions to revise the local urbanization rate if necessary.

It is worth developing a system of coherent of urbanization rates in China which are comparable in time, regions, and organizations.

Funding: Supported by the National Natural
Science Foundation of China (Grant No.: 42071375).

doi: $10.46234 / \mathrm{ccdcw} 2022.007$

\# Corresponding author: Jinfeng Wang, wangjf@lreis.ac.cn.

${ }^{1}$ State Key Laboratory of Resources and Environmental Information System, Institute of Geographic Sciences and Natural Resources Research, Chinese Academy of Sciences, Beijing, China; ${ }^{2}$ University of Chinese Academy of Sciences, Beijing, China; ${ }^{3}$ Center for Regional Agriculture and Rural Development, Institute of Geographic Sciences and Natural Resources Research, Chinese Academy of Sciences, Beijing, China.

Submitted: June 12, 2021; Accepted: December 10, 2021

\section{REFERENCES}

1. Davis K. The urbanization of the human population. Sci Am 1987; 213(3):40 - 53. http://dx.doi.org/10.1038/scientificamerican0965-40.

2. United Nations. World urbanization prospects: the 2009 revision. 2010. https://www.un.org/en/development/desa/population/publica tions/pdf/urbanization/WUP2009_Wallchart_Urban-Agglomerations_ Final.pdf. [2021-6-11]

3. Gong P, Liang S, Carlton EJ, Jiang QW, Wu JY, Wang L, et al. Urbanisation and health in China. Lancet 2012;379(9818):843 - 52. http://dx.doi.org/10.1016/S0140-6736(11)61878-3.

4. $\mathrm{Li} \mathrm{H}$. International phenomenon observation of urbanization rate exceeding 50\% threshold: implications for China. Urban Plan Forum 2013(1):43 - 50. http://dx.doi.org/10.3969/j.issn.1000-3363.2013.01. 007. (In Chinese).

5. The World Bank. World development indicators. In: World Bank Publications. vol. 3.12 Urbanization. 2014. http://wdi.worldbank.org/ table/3.12.

6. National Bureau of Statistics of the People's Republic of China. Demographic statistics. http://www.stats.gov.cn/tjzs/tjbk/nsbzb/ 201402/P020140226567304137520.pdf. [2021-6-11]. (In Chinese).

7. Qi W, Liu SH, Jin HR. Calculation method and spatial pattern of urbanization rate of registered population in China. Geogr Res 2017;36(4):616 - 32. http://dx.doi.org/10.11821/dlyj201704002. (In Chinese)

8. National Development and Reform Commission. National new urbanization planning (2014-2020). https://www.ndrc.gov.cn/fggz/ fzzlgh/gjfzgh/201404/t20140411_1190354.html. [2021-6-11]. (In Chinese)

9. Chan KW, Zhang L. The Hukou system and rural-urban migration in China: processes and changes. China Quart 1999;160:818 - 55. http:// dx.doi.org/10.1017/S0305741000001351.

10. Shanghai will implement the residence permit system from next month (hot spot interpretation). 2013. http://politics.people.com.cn/n/2013/ 0620/c1001-21902572.html. [2021-6-11]. (In Chinese).

11. Wang GX, Fan YM. On the present reform of China's household registration system. J Xinjiang Univ (Philos, Humani Soc Sci) 2014;42(5):27 - 31. http://dx.doi.org/10.13568/j.cnki.issn1000-2820. 2014.05.019. (In Chinese).

12. Li AM. Peri-urbanization in China. Popul Res 2013;37(4):80-91. https://t.cnki.net/kcms/detail?v=HsY65W21-29CuNWRATiSz U0hJflIOzMLBG8i4zoYcSjLDIms35zZOsMHgsgGlouBjSffcfc95zIc_v 5a2H1PfyamhA_i4Xu-EOXIaorpHVrRq_30MomEuQ==\&uniplat form=NZKPT. (In Chinese).

13. Yang SP, Tang FF, Wu X. The inverted U-shaped curve between Chinese urban-rural income inequality and urbanization rate. Manag Rev 2015;27(11):3 - 10. http://dx.doi.org/10.14120/j.cnki.cn11-5057/ f.2015.11.001. (In Chinese).

14. Liang W, Yang M, Zhang YW. Will the increase of the urbanization rate inevitably exacerbate haze pollution? A discussion of the spatial spillover effects of urbanization and haze pollution. Geogr Res 2017;36(10):1947 - 58. http://dx.doi.org/10.11821/dlyj201710011. (In Chinese). 